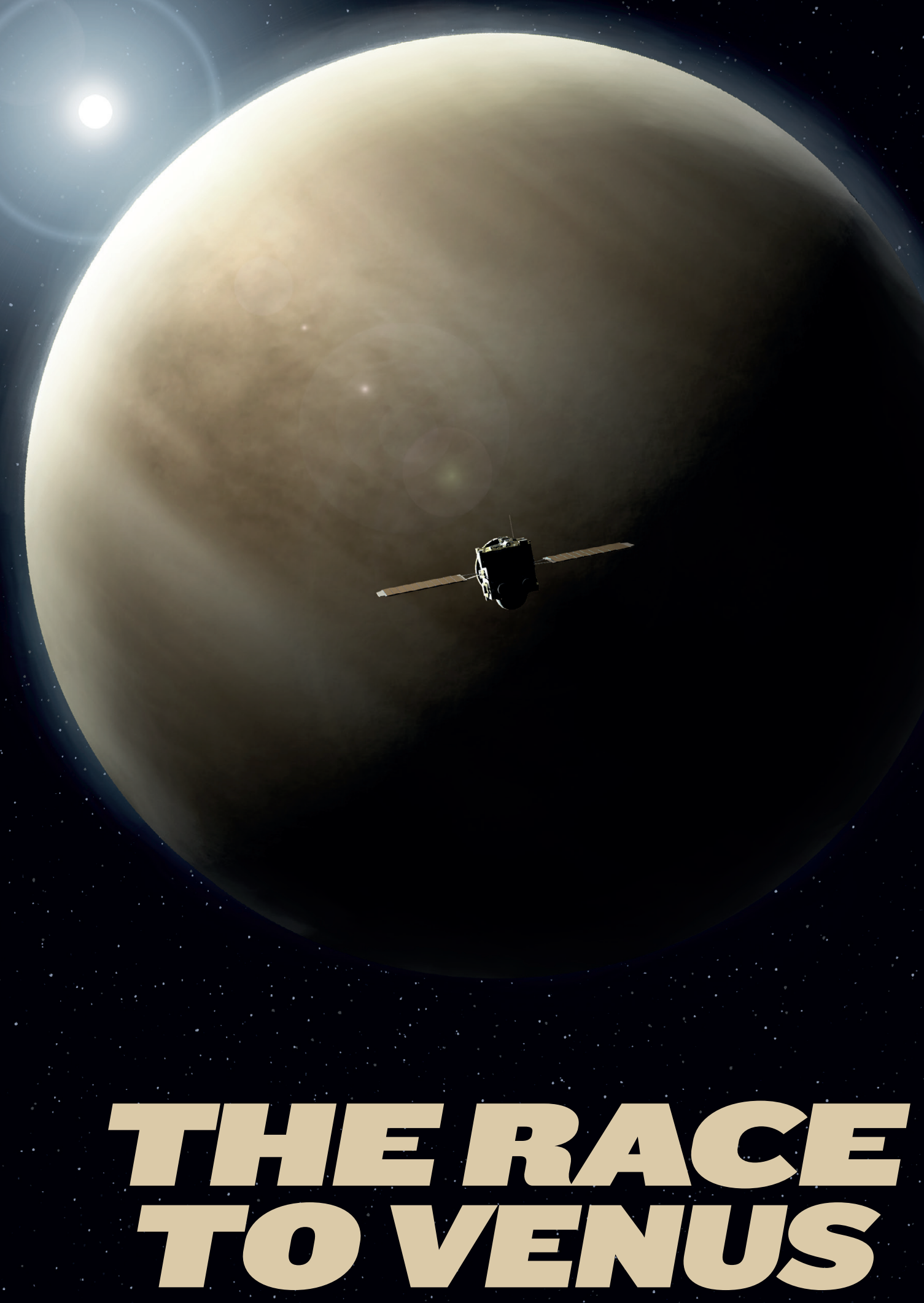

After decades of neglect, the world's space agencies can no longer resist the pull of Earth's evil twin. 


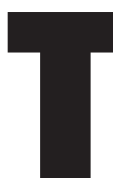
he helicopter fell like a stone. It dropped by more than 1,500 metres over Maryland, twisting slightly as the ground grew rapidly closer. Although this was all according to plan, that didn't settle James Garvin's nerves. Nor did the realization that his seat belt wasn't fully fastened - a moment that sent his heart rate skyrocketing.

Then, a mere 6 metres above the ground, the ride got even wilder when the pilots pulled the aircraft out of the fall and climbed skywards, only to fall again. The helicopter dropped ten times that day. And each time, Garvin pointed a camera towards the ground through the open door in an attempt to measure the topography of a rock quarry below - from massive boulders to smooth sheets of sand. Although his interests were hardly terrestrial.

Garvin, the chief scientist at NASA's Goddard Space Flight Center in Greenbelt, Maryland, is the principal investigator on a proposed mission to Venus that would drop a probe through its atmosphere. That's why he hired two pilots in August 2016 to plunge a helicopter towards the ground while he tested what a Venus probe might be able to photograph. The harrowing ride was worth it: researchers would love to get their hands on pictures of Venus with so much detail that the scenery would become familiar. "These images would be like you landing in your backyard," he says.

Garvin is not the only scientist preparing such a daring mission. Nearly every space agency around the globe is currently sketching a proposal to explore our long-neglected neighbour. The Indian Space Research Organisation (ISRO) will be first to lift off when it launches an orbiter to Venus in 2023. The United States could follow close behind. Garvin and his colleagues are one of a handful of groups that will soon propose missions to NASA that, if selected, would take off in 2025. The European Space Agency (ESA) is currently considering a proposal to send an orbiter to Venus in 2032. And the Russian space agency Roscosmos is working in collaboration with the United States to send a daring mission to the planet any time from 2026 to 2033, which would include an orbiter, a lander that would send back short-term readings and a research station that would survive for much longer.

The new-found interest stands in stark contrast to the fact that nations have long overlooked Venus in favour of chasing Mars, asteroids and other planets. Over the past 65 years, for example, NASA has sent 11 orbiters and 8 landers to Mars, but just 2 orbiters to Venus - and none since 1994. This has not been for lack of scientific interest. Since the mid-1990s, US scientists alone have submitted nearly 30 Venus proposals to NASA. None has been approved.

But momentum is building to explore Venus, in part because scientists say it could hold the secret to understanding what makes a planet habitable. Once Earth's twin, today Venus is a hellish abode where surface temperatures reach more than $400^{\circ} \mathrm{C}$, atmospheric pressures slam down with enough force to crush heavy machinery and clouds of sulfuric acid blow through the sky. If researchers could decipher why conditions on Venus turned so deadly, that would help them to assess whether life might exist on some of the thousand-plus rocky worlds that astronomers are discovering throughout the Galaxy.

As the scientific justification has grown for exploring Venus, planetary scientists are dreaming up new ways to study the planet and are building technology in the laboratory that can survive the horrendous conditions on its surface. And with India leading the way, there might soon be a parade of probes heading towards the second rock from the Sun (see 'Visiting Venus').

"It might be the start of a new decade of Venus," says Thomas Widemann, a planetary scientist at the Paris Observatory.

\section{DOUBLE TROUBLE}

When humanity initially reached towards the stars, it ventured to Venus. Our neighbour was the target of the first successful interplanetary probe (United States, 1962); the first planet on which a mission crashed (Soviet Union, 1965); and the first alien world to host a successful landing (Soviet Union, 1970). It was during this space race to Venus that scientists discovered a torrid and toxic world.
That could explain why interest in Venus dwindled. Scientists quickly realized that this planet would not be a home for future human exploration, nor an outlet on which to search for life. It would be downright difficult to study at all, even for short amounts of time.

And yet in so many ways - size, density, chemical make-up Venus is Earth's double. Recent research has even suggested that it might have looked like Earth for three billion years, with vast oceans that could have been friendly to life. "That's what sets my imagination on fire," says Darby Dyar, a planetary scientist at Mount Holyoke College in South Hadley, Massachusetts. "If that's the case, there was plenty of time for evolution to kick into action."

That could mean that Venus was (somewhat surprisingly) the first habitable planet in the Solar System - a place where life was just as likely to arise as it was on Earth. That alone is a reason to return to the former ocean world. "Why are we investing so much time looking for life on Mars when it only had liquid water for 400 million years?" Dyar asks. "And then there's Venus with three billion years of water and no one loves her."

Yet there's no question that something went terribly wrong. Although Earth and Venus began in a similar fashion, the two have wandered down drastically different evolutionary paths - diverging perhaps as recently as 715 million years ago. That might seem like a reason not to visit, but scientists now argue that it makes the planet even more intriguing. If researchers could only understand

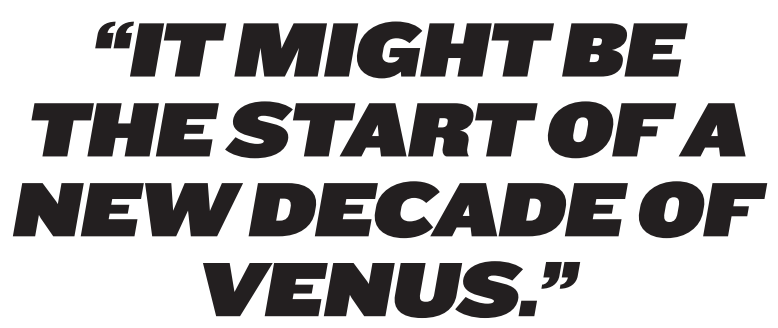

what caused Venus to undergo such a deadly metamorphosis, they might gain a better understanding of what caused Earth to become such a haven for life.

"Venus plays a key role in understanding ourselves here - how life evolved on our own planet," says Adriana Ocampo, science programme manager at NASA headquarters in Washington DC.

It is a crucial question now that astronomers have uncovered thousands of planets outside our Solar System - many of which are rocky worlds that orbit their stars at distances similar to those of Venus and Earth from the Sun. That means that many of these worlds could be Venus-like. "There is growing realization within the exoplanet community that Venus is the best analogue in the Solar System for many of the rocky exoplanets we have found," says Laura Schaefer, an astronomer at Stanford University in California who studies exoplanets.

\section{OFF THE RADAR}

With such a tantalizing question left unanswered, it's easy to see why ISRO's return to Venus has created so much excitement. "I'm thrilled that ISRO is doing this," Dyar says. "I'm thrilled that the international community is taking note of Venus and proposing missions. That's fantastic."

Although the ISRO mission is enveloped in a cloud of secrecy (Nature e-mailed and called project scientists dozens of times, to no avail), it's clear that the agency plans to send an orbiter smothered in instruments. When ISRO announced the mission late last year, it published a list of a dozen instruments proposed by Indian scientists that have already been chosen - providing a sneak peek of the mission. Of those sensors, two will map the planet using radar, which is arguably the best method to peer through Venus's dense clouds and trace its surface from orbit.

That said, ISRO is a relatively young space agency with a limited 


\title{
HISTORICAL MISSIONS
}

O United States

1962 Mariner 2

First successful fly-by. Confirmed very

high surface temperature and pressures.

\author{
Soviet Union
}

1973 Mariner 10

First close-up

images of Venus.

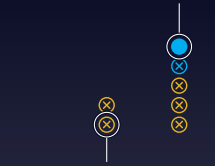

1961 Sputnik 7

First failed probe attempt.

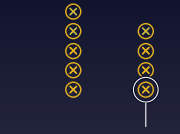

1965 Venera 3

First spacecraft

to crash on surface.

\section{๑̊日}

1967 Venera 4

First craft to

successfully drop probes that explored atmosphere.

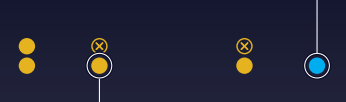

\section{Venera 7}

First lander to send

data back from the

surface. Survived

for 23 minutes.

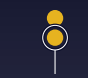

1975 Venera 9

Lander sent back

first pictures from

Venus's surface.

\section{Pioneer Venus 1,2}

Two missions explored atmosphere, surface and space environment and sent down five atmospheric probes.

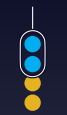

\section{VSTING VEIIS}

RESEARCHERS ARE EAGER TO FIND OUT WHY EARTH'S SISTER PLANET TURNED INTO SUCH A HELLISH PLACE.

\section{BY RICHARD MONASTERSKY} AND SHANNON HALL

DESIGN BY JASIEK KRZYSZTOFIAK

From a distance, Venus looks a lot like Earth. It's about the same size and density, and is our closest planetary neighbour. But when people first started exploring Venus using robotic probes, they found that it was hostile - fiendishly hot with an oppressively heavy, acidic atmosphere. Not the sort of place to bring the family. Yet the differences are what intrigue scientists. They want to find out what made the greenhouse effect on Venus go into overdrive and turn the planet toxic.

\section{WATER MYSTERY}

Earth, Mars and Venus all had liquid water on their surfaces after a period of intense bombardment by meteorites in the early Solar System. Whereas Mars lost its water early, Venus probably kept its supply for a long stretch of its history before the water boiled away. Researchers want to decipher when that happened and why.

- Volcanic activity Liquid water

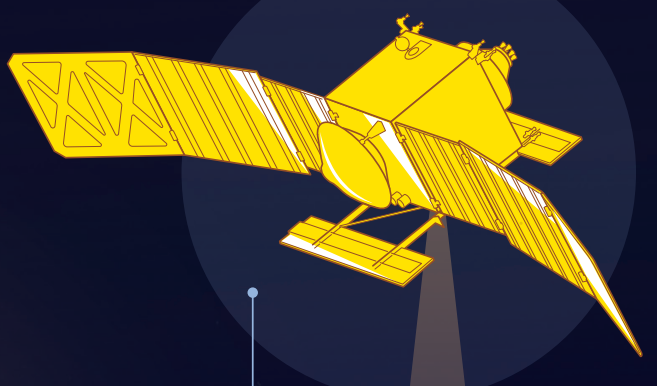

VERITAS, DAVINCI UNITED STATES

Two teams of researchers have proposed relatively low-cost Venus missions to NASA. VERITAS would use high-resolution radar to map the planet's topography, whereas DAVINCI would drop a probe through the atmosphere to study its composition and snap pictures of the ground. If one is selected, it could fly in the mid-2020s.

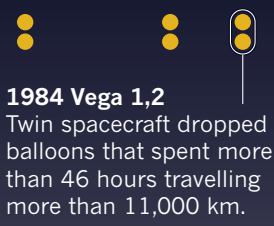

1975


1989-94 Magellan

Used radar to produce the

highest-resolution maps of the surface,

achieving near-global coverage. Revealed

that volcanic eruptions resurfaced much of

the planet in the past 500 million years.<smiles>COCCO</smiles>

\section{Galileo}

Swung past Venus

on its trip to Jupiter.

2005-14 Venus Express

Orbiter detected evidence for geologically

young lava flows, suggesting eruptions in past few millions years or less. Measured changes in speed of rapidly moving atmosphere, which circles planet in about four Earth days.

\section{O}

\section{Cassini}

Passed Venus twice

to gain speed for its trip to Saturn.
( ) 0

\section{Messenger}

Flew past Venus twice on its way to Mercury.
2010 Akatsuki (active mission) Failed to reach orbit initially, but was successfully inserted into orbit five years later and collected meteorological data about the planet's atmosphere.
1990

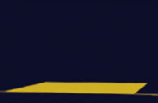

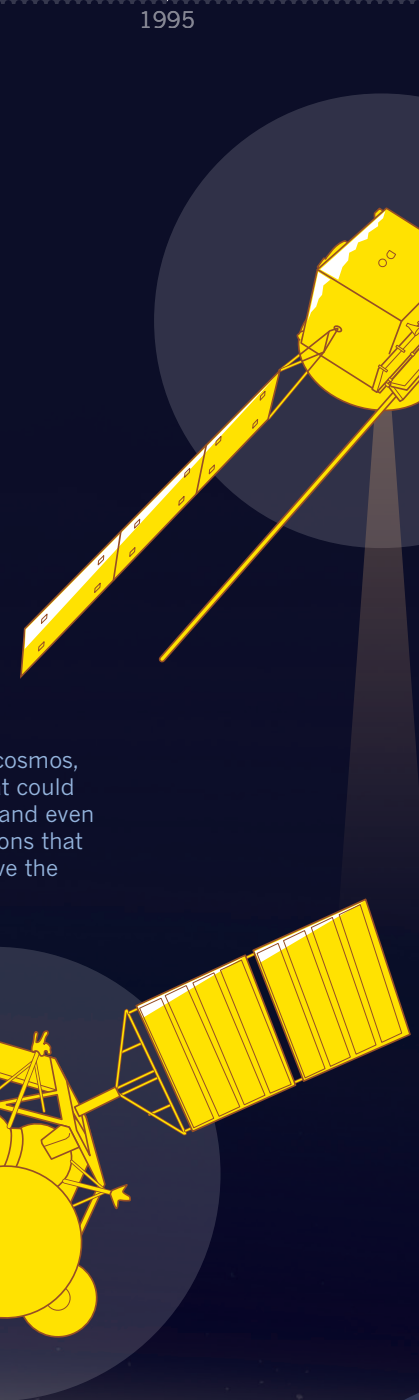

2000

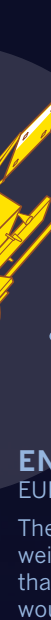

VENERA-D

\section{RUSSIA}

Russia's space agency, Roscosmos,

is considering a mission that could

include an orbiter, a lander and even

a balloon to look for conditions that

might support life high above the

planet's sizzling surface.

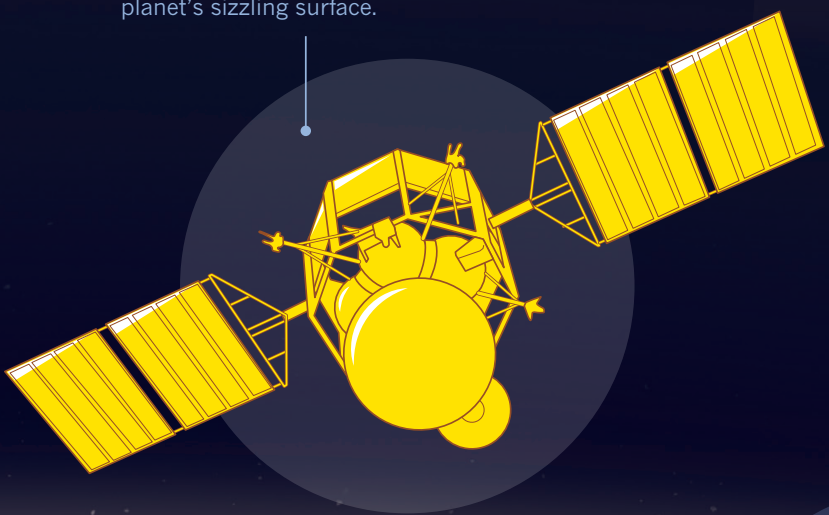

\section{LLISSE}

UNITED STATES

NASA researchers are developing a Long-Lived In-Situ Solar System

Explorer (LLISSE) that could

survive on the surface for weeks or months to collect data about

conditions and how they change.

\section{VOLCANISM}

Evidence suggests that there has been volcanic activity on Venus in the past few million years, and researchers are eager to determin whether any continues today.
2005

2010

\section{PLANETARY FACELIFT}

One major question about Venus is whether it has plate tectonics - the process that describes how a planet's outer shell is broken into big pieces that shift around and regularly reshape the surface. On Earth, plate tectonics helps to regulate the planet's temperature.

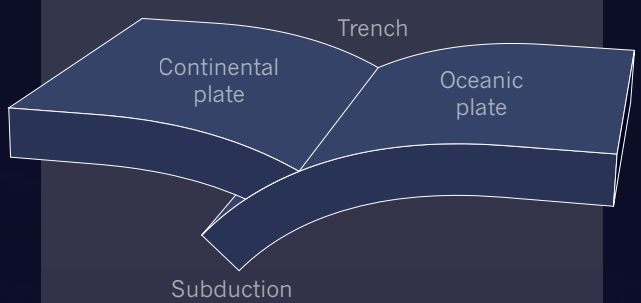

Subduction happens when one plate rides up over another, forcing the lower plate to dive into the interior. Researchers suggest that a curved feature on Venus known as Artemis corona resembles the Aleutian trench, which is a site of active subduction on Earth.

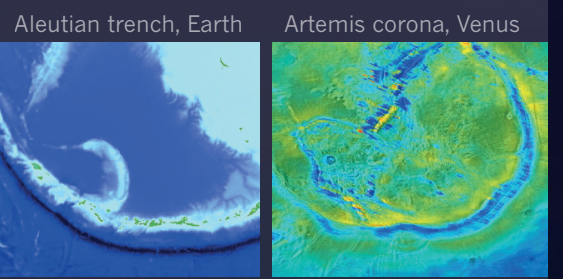

If plate tectonics is happening on Venus, we might not be able to spot the signs in the best available images of the planet. The San Andreas fault, for example, would not be visible in topographic radar data that have been degraded to the same resolution as the images captured by the Magellan spacecraft. But the fault does appear clearly on topographic radar images taken at a resolution that could be achieved in a future Venus mission.

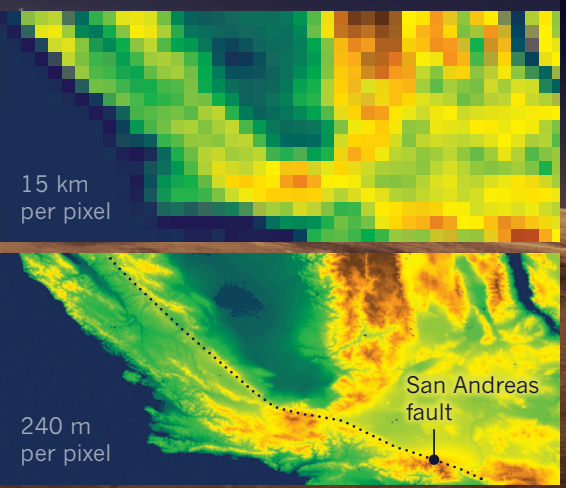


number of successful landings on the Moon and Mars. And, similar to programmes from other fledgling agencies, India's first Venus mission might be a proof of concept that is less focused on science than on engineering. But given that even basic information on Venus is lacking, any small step will contribute to science.

One such contribution might be new maps of Venus's surface features - a major step up, scientifically. The last mission to map the planet's topography was NASA's Magellan orbiter, which launched 30 years ago. Although those radar maps remain the foundation of Venusian geoscience today, they show topographic details at a horizontal resolution of just 10-20 kilometres per pixel, on average (the image resolution can be two orders of magnitude higher). With such limited topographic data, researchers have a blurry view of Venus's geology — but the available maps do hint that plate tectonics might be kicking into action today.

That is particularly tantalizing, because many scientists think that tectonic activity is a crucial ingredient for life. Tectonic plates - those interlocking slabs of Earth's crust that fit together like puzzle pieces constantly move about, with some slipping below others and diving into the planet's interior in a process called subduction. Over millions of years, that process has kept Earth from growing too hot or cold by cycling heat-trapping carbon dioxide between the atmosphere and the deep Earth. It acts as a natural thermostat, which might mean that fidgety planets are more likely to host life.

As such, scientists are eager to decipher the conditions that allow plate tectonics to arise. That is why Suzanne Smrekar, a planetary scientist at NASA's Jet Propulsion Laboratory in Pasadena, California, has her eye on Venus - especially some spots that look eerily similar to locations on Earth where subduction is happening now. Scientists agree that subduction is the first step in the path towards plate tectonics, and yet there are no clear signs of large moving plates on Venus - at least not in the decades-old maps produced by Magellan. The San Andreas fault, which forms the tectonic boundary between Earth's Pacific Plate and North American Plate, for example, varies in width from metres to a kilometre - too narrow to show up in Magellan topographic data.

But future maps might uncloak such tectonic features. Smrekar is the principal investigator on a potential mission, known as VERITAS, that she and her team will soon propose to NASA. The geophysical mission would use radar to map Venus's topography in higher resolution than before - increasing the accuracy from roughly 15 kilometres to 250 metres - and allowing scientists to uncover features as small as the San Andreas fault for the first time.

Although scientists don't know what they will find, it is possible that they will uncover evidence for past plate tectonics. Such a discovery would explain why Venus preserved an Earth-like environment for billions of years, Smrekar says - that natural thermostat would have kept $\mathrm{CO}_{2}$ in check. And it would explain how Venus turned hellish. When plate tectonics ceased, $\mathrm{CO}_{2}$ levels would have increased in the atmosphere and trapped so much heat that the oceans vaporized.

But that is only one possible finding. Some scientists are keen to study the planet's atmosphere, which holds another, equally tantalizing set of secrets.

The probe that Garvin is proposing, called DAVINCI, would drop through the atmosphere to measure the brew of toxic compounds. The isotopes of noble gases, particularly xenon, could give scientists a window into the planet's volcanic history and reveal whether Venus started with as much water as Earth did. "Venus's atmosphere is this lurking laboratory for telling us about its history," Garvin says. "And really, most of the measurements in the atmosphere are woefully incomplete." In addition, the probe would take images of the surface - thanks to Garvin's terrifying helicopter flights - until the last few seconds before it hits.

Both VERITAS and DAVINCI will enter NASA's competition on 1 July for future Discovery missions - a line of low-cost planetary probes that each cost just US $\$ 500$ million. And rumour has it they're not alone. There could be as many as five Venus missions (including a balloon) among the dozens of proposals to study various objects in space. NASA's last Discovery competition, in 2015, for example, considered 27 proposals - from probes that would explore asteroids, moons and planets across the Solar System to telescopes that would image its outer reaches - before choosing two missions that would fly.

At the end of this year, the administration will select a few missions for further study, and it will pick the final project in two years' time. Both Smrekar and Garvin are hopeful that each of their missions will be selected, in part because they proposed similar missions in the last Discovery competition, and both were chosen for further study, along with three others. If one of the Venus missions is successful, it will launch in the mid-2020s.

Even after that time frame, Venus might remain a hub for interplanetary activity. ESA recently picked a Venus probe called EnVision, along with two other finalists, as a mission that could fly as soon as 2032. Like VERITAS, EnVision is an orbiter. But unlike VERITAS, which would map the entire planet to a resolution of 15-30 metres, EnVision will analyse small portions of the planet with a resolution as high as 1 metre. At that level of accuracy, scientists might be able to see the landers that the Soviet Union left behind.

They could even pick out the type of rock that the landers are resting on. This is possible because astronomers in the early 1990s found that certain wavelengths of light can pass through the $\mathrm{CO}_{2}$ haze that hides the Venusian surface. An orbiter carrying a spectrometer tuned to these transparent 'windows' in the light spectrum could analyse the composition of the planet's surface from above the clouds. That's an exciting prospect, especially if scientists could spot granite.

Like basalt, granite forms when molten magma cools and hardens. But unlike basalt, the recipe for granite typically requires copious amounts of water - which happens on Earth when water-rich oceanic

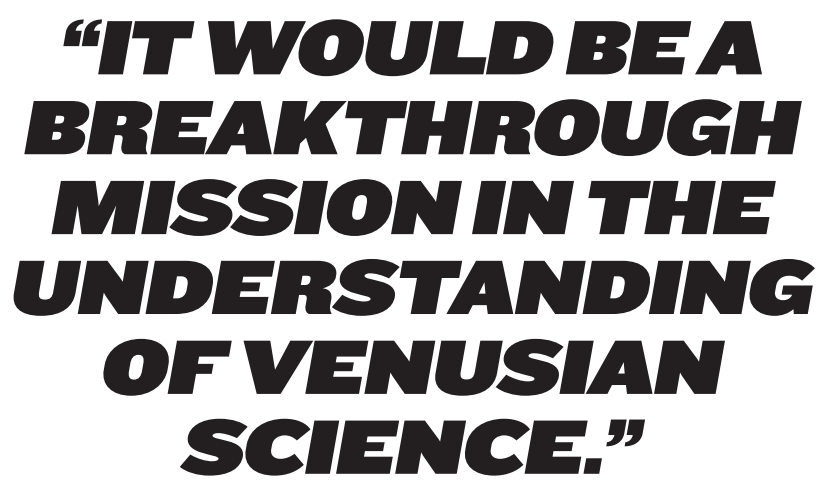

crust subducts below another plate. So if Venus is found to be rich in granite, it probably once overflowed with liquid water.

And that might be the best hint yet that the planet was formerly a pale blue dot vastly similar to Earth today — another clue in their diverging stories.

The problem is that there are only five narrow spectral windows in Venus's atmosphere that are actually transparent. With such little information, scientists weren't sure whether they would be able to differentiate between granite and basalt. So Jörn Helbert, a planetary scientist at the Institute of Planetary Research in Berlin, subjected both types of rock to Venus-like conditions and imaged them through those narrow frequency bands. His experiment suggested that the two rock spectra look radically different from one another, and that future missions could make use of the windows. He and his colleagues built an instrument to use this trick to map any granite on the Venusian surface. It would fly on both VERITAS and EnVision.

\section{WITHIN REACH}

To truly understand the surface, a number of scientists want to actually land a craft on our toxic twin - a feat that has not been achieved for 35 years. Although the Soviet Union sent several landers to Venus, the ones that survived quickly succumbed to the planet's harsh environment: 


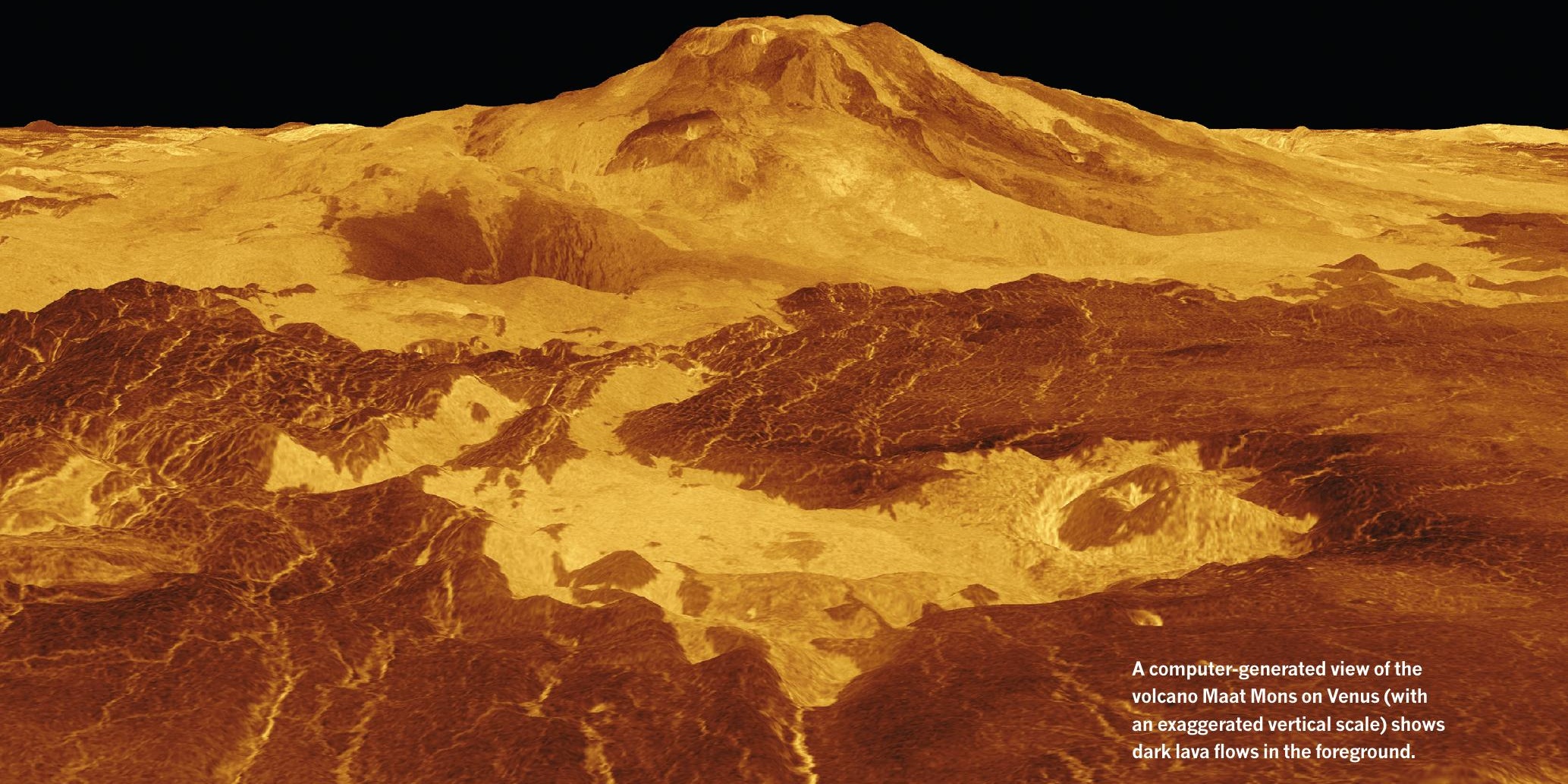

the longest-lasting one persevered for a mere 127 minutes.

But scientists hope to break that record, and have already designed technology that can last not just minutes, but months. A team at NASA's Glenn Research Center in Cleveland, Ohio, is building a station that should survive for at least 60 days. Instead of using its bulk to absorb heat or countering the conditions with refrigeration, the lander would use simple electronics made of silicon carbide (a hybrid of silicon and carbon commonly used in sandpaper and fake diamonds) that can withstand the Venusian environment. "That's the real game changer for Venus exploration," says Philip Neudeck, an electronics engineer at the Glenn Research Center.

The team has already tested the circuits in a Venus simulation chamber - a 14-tonne stainless-steel tank that can imitate the temperature, pressure and specific chemistry of the Venusian surface. The researchers have used those results to design a stationary surface probe called LLISSE (Long-Lived In-Situ Solar System Explorer), which should be ready for flight by the mid-2020s and will be offered to other countries. "Any mission to Venus is welcome to use LLISSE," says electronics engineer Gary Hunter, also at the Glenn Research Center. He and the team were careful to design a lander that would be only as large as a toaster - making it both small and light enough that it can hitch a ride on a number of future missions.

Despite its small size, LLISSE would be able to record temperature, pressure, wind speed, wind direction, the amount of solar energy at the surface and a few specific chemicals in the low atmosphere. And it would do so for months, providing crucial input for models of the Venusian atmosphere. "Imagine if one tried to say one knew the weather on Earth by going outside for 127 minutes," Hunter says. That is the current record for any weather data on Venus.

Already, scientists at Roscosmos are eager to use this new technology. In a joint proposal with NASA, they are working on a mission known as Venera-Dolgozhivuschaya (where the latter means longlasting), or Venera-D for short. Such a mission would comprise a menagerie of components - an orbiter, a lander and a long-lived station. The lander would include a number of advanced instruments but would last for only a few hours; the long-lived station would be simpler in design but continue taking measurements for months. The station is likely to be NASA's LLISSE.

At least, that's the baseline architecture - but the mission could include even more. This year, the Venera-D team released a report that covered a number of potential additions, including a balloon that could explore the cloudy atmosphere. And that opens up the possibility of searching for life on Venus. All the other missions proposed so far aim to assess whether Venus was habitable in the past. But a balloon might be able to look for life in the only environment where it might survive today: the skies.

"You can imagine that there's somewhere in between the hot hostile surface and the cold vacuum of outer space where there are conditions - like Goldilocks' - that are just right for life," Dyar says. Not only would that layer have a pleasant temperature, but it could also have nutrients, liquid water and energy from the Sun. If life ever existed on the planet, it might have been carried up to the clouds and survived there after the surface turned toxic.

But even without a balloon, the three main components of the Venera-D mission would provide excellent science, argues Ocampo. "It would be a breakthrough mission in the understanding of Venusian science," she says. "We haven't had a mission similar to this before."

Unfortunately, Venera-D has not yet been selected, and many scientists have expressed some concern over the fact that it has long been discussed and yet still does not have the appropriate funding. But Ludmila Zasova, the lead scientist on the Venera-D mission at the Space Research Institute in Moscow, hopes that might change this year. It's not the only big ambitious mission in the works. Some US teams plan to submit Venus projects to NASA's New Frontiers programme, which is capped at $\$ 1$ billion, and to the Flagship mission programme, which costs even more. Because Venus proposals have done well in past competitions (often falling just behind the selected proposals), scientists think there is a good chance that they will now rise to the top.

With every space agency eyeing our neighbour, Venus is likely to receive a fleet of visitors over the next few decades. And although they all plan to address the question of habitability in one way or another, Garvin is convinced that whatever they find, it will be "beyond our wildest dreams". Perhaps they will prove that Venus was formerly an ocean world. Or maybe they'll discover that it's tectonically active today. "We need to find out," he says. "Because she's waiting to tell us something and I would hate to miss the boat." 